\title{
The good, the bad, and the ugly of calcium supplementation: a review of calcium intake on human health
}

This article was published in the following Dove Press journal:

Clinical Interventions in Aging

\author{
Kelvin Li, ${ }^{1, *}$ Xia-Fang Wang, ${ }^{2,3, *}$ \\ Ding-You Li, ${ }^{4}$ Yuan-Cheng \\ Chen, ${ }^{2}$ Lan-Juan Zhao, ${ }^{\prime}$ Xiao- \\ Gang Liu, ${ }^{5}$ Yan-Fang Guo, ${ }^{6}$ Jie \\ Shen, ${ }^{2}$ Xu Lin, ${ }^{2}$ Jeffrey Deng, ' \\ Rou Zhou, ${ }^{2}$ Hong-Wen Deng ${ }^{1,7}$
}

'Center for Bioinformatics and Genomics, Department of Global Biostatistics and Data Science, Tulane University, New Orleans, LA 70II2, USA; ${ }^{2}$ Department of Endocrinology and Metabolism, The Third Affiliated Hospital of Southern Medical University, Guangzhou, Guangdong 510630 , People's Republic of China; ${ }^{3}$ Department of Endocrinology and Metabolism, Hengyang Central Hospital, Hengyang, Hunan 421000, People's Republic of China; ${ }^{4}$ Department of Gastroenterology, Children's Mercy Kansas City, University of Missouri Kansas City School of Medicine, Kansas City, MO 64I08, USA; ${ }^{5}$ School of Life Science and Technology, Xi'an Jiao Tong University, Xi'an, Shanxi 7l0049, People's Republic of China; ' $I n s t i t u t e$ of Bioinformatics, School of Basic Medical Science, Southern Medical University, Guangzhou, Guangdong 5 I 0515 , People's Republic of China; ${ }^{7}$ School of Basic Medical Science, National Clinical Research Center for Geriatric Diseases, Xiangya Hospital, Central South University, Changsha, Hunan 410078, People's Republic of China

*These authors contributed equally to this work
Correspondence: Hong-Wen Deng Center for Bioinformatics and Genomics, Department of Global Biostatistics and Data Science, Tulane University, 1440 Canal Street, Suite 200I, New Orleans, LA 70II2, USA $\mathrm{Tel}+\mathrm{I} 5049881310$

Fax +I 504988 I706 Email hdeng2@tulane.edu

\begin{abstract}
Calcium is an important integrative component of the human body and critical for human health. It has been well established that calcium intake is helpful in the prevention and treatment of osteoporosis, which has become one of the most serious public health problems across the world. However, community-dwelling adults with and without osteoporosis are rarely concerned or even not aware of the potential side effects of high or inappropriate doses of calcium intake. Some recent studies have revealed that excessive calcium intake might increase the risks of cardiovascular diseases. The purpose of this article was to review the health benefits, costs, and consequences of calcium supplementation on osteoporosis/osteoporotic fractures, cardiovascular events, kidney stones, gastrointestinal diseases, and other important diseases. In the end, we suggest that calcium supplementation should be prescribed and taken cautiously, accounting for individual patients' risks and benefits. Clearly, further studies are needed to examine the health effects of calcium supplementation to make any solid recommendations for people of different genders, ages, and ethnicities.
\end{abstract}

Keywords: calcium, osteoporosis, osteoporotic fractures, cardiovascular diseases, kidney stones, gastrointestinal diseases

\section{Introduction}

Calcium supplementation is a widespread practice in different age-groups and has been promoted widely to improve bone density. ${ }^{1}$ The public generally believes that calcium is always good for health, owing largely to successful marketing and various clinical practice guidelines (Table 1). Based on the published data, $61 \%$ of women aged $>60$ years received calcium supplements in 2003-2006 in the United States. ${ }^{2}$ As a result, calcium supplementation has become a billion dollar market in recent years and has been taken by millions of both men and women, children, adults, and the elderly wishing to improve their skeletal health.

People may get more calcium from dietary intake or calcium supplementation. Due to the limited availability of calcium-rich foods and dietary habits, it is not always possible for people to take more and sufficient dietary calcium. Thus, there is a role for calcium supplementation for patients with inadequate dietary calcium intake. Initial studies suggested that dietary calcium had a greater effect on bone building due to its better absorption than supplemental calcium, but further studies are needed to fully elucidate whether one is better than the other to improve bone density. ${ }^{3}$

Recently, increasing concerns have been raised regarding whether indiscriminate calcium supplementation is safe. A meta-analysis by Bischoff-Ferrari et al demonstrated 
Table I Calcium intake clinical practice guidelines for osteoporosis in different populations

\begin{tabular}{|l|l|l|l|l|}
\hline Source & Year published & Populations & $\begin{array}{l}\text { Recommended intake } \\
\text { (mg/day) }\end{array}$ & References \\
\hline $\begin{array}{l}\text { UK National Osteoporosis } \\
\text { Guideline Group }\end{array}$ & 2017 & $\begin{array}{l}\text { Postmenopausal women } \\
\text { Old people }\end{array}$ & $\begin{array}{l}700-1,200 \\
\text { Adults }\end{array}$ & 68 \\
\hline Osteoporosis New Zealand & 2017 & $\begin{array}{l}\text { Men (aged 50-70 years) } \\
\text { Women aged }>51 \text { years } \\
\text { Men aged }>71 \text { years }\end{array}$ & $\begin{array}{l}\text { I,000 } \\
\text { I,200 } \\
\text { I,200 }\end{array}$ & 69 \\
\hline National Osteoporosis Foundation & 2014 & Adults & $700-800$ & 76 \\
\hline None & Adults & 1,200 & 71 \\
\hline None & 2012 & $\begin{array}{l}\text { Adults } \\
\text { Postmenopausal women } \\
\text { Old people }\end{array}$ & $\begin{array}{l}800 \\
\text { I,000 } \\
\text { I,000 }\end{array}$ & 72 \\
\hline $\begin{array}{l}\text { Chinese Society of Osteoporosis } \\
\text { and Bone Mineral Research }\end{array}$ & 2012 & People aged $>50$ years & $\mathrm{I}, 000$ & 73 \\
\hline Best Practice Guidelines Committee & 2010 & & \\
\hline
\end{tabular}

an increased hip fracture risk with calcium supplementation. ${ }^{4}$ A recent meta-analysis of randomized clinical trials showed that calcium supplementation was not associated with a low risk of fractures among community-dwelling older adults. ${ }^{5}$ There has been a concern for a significant increase in the risk of cardiovascular diseases with high supplemental calcium intake in men. ${ }^{6-8}$

Given the emerging dilemma regarding calcium supplementation, the present article reviews discusses the potential benefits and side effects of calcium supplementation on health and diseases such as osteoporosis/osteoporotic fractures, cardiovascular events, kidney stones, gastrointestinal diseases, and others.

\section{The basics: the role of calcium}

It is well established that calcium is an extremely important and integrative component of human body, with $99 \%$ of the body's calcium being contained within the skeleton. ${ }^{9}$ Plasma calcium homeostasis plays a vital role in maintaining human life activities, such as maintenance of the skeleton, regulation of hormonal secretion, transmission of nerve impulses, and vascular activities. ${ }^{10-12}$ As shown in Figure 1, dietary calcium is absorbed mainly in the small intestine. Through circulation, it is mostly deposited into bones. Excessive or unabsorbed calcium is excreted in urine and feces. ${ }^{10}$ The homeostasis of calcium is mainly maintained by both parathyroid hormone (PTH) and calcitonin. ${ }^{13}$ When serum calcium level drops, PTH promotes calcium releases from the bones and stimulates reabsorption of calcium by the kidney tubules. In addition, PTH indirectly increases calcium absorption in the intestine via calcitriol, which is produced by the kidney and is the hormonal form of vitamin D. On the other hand, when serum calcium level rises, calcitonin would suppress calcium release from the bones ${ }^{10}$ and reduce calcium reabsorption by the kidney tubules. ${ }^{14}$

\section{Potential beneficial effects of calcium supplementation Osteoporosis}

As calcium is one of the constituents of bone, the majority of researches considered that high calcium intake may result in higher bone density. ${ }^{1}$ According to the current status of our knowledge and understanding, improving accrual of peak bone mass and slowing the loss of bone after reaching the peak are two key factors in the prevention of osteoporosis. Moreover, bone mass grows most quickly during adolescence, ${ }^{15}$ thus, the prevention of osteoporosis should ideally start from this time. ${ }^{16}$ Importantly, calcium supplementation, together with vitamin D supplementation, is supported by the accumulating evidence for patients at high risk of calcium and vitamin D insufficiency and for those who receive treatment for osteoporosis. ${ }^{17}$

Interestingly, some studies illustrated that calcium supplementation played a protective role for bone health, improving bone mass density (BMD) and decreasing morbidity of osteoporosis and osteoporotic fractures in different genders and age-groups. ${ }^{18}$ For children or adults, best evidence (grade A) is available for positive effects of calcium intake on the prevention of osteoporosis according to the National Osteoporosis Foundation (NOF). ${ }^{16}$ In addition, the administration of calcium was also shown to stave off fracture. ${ }^{19}$ Radford et al investigated the effects of calcium on fracture incidence and BMD after calcium supplement discontinuation; they concluded that the fractures in forearm and vertebrae were significantly decreased, but the positive benefits on BMD observed in the original 


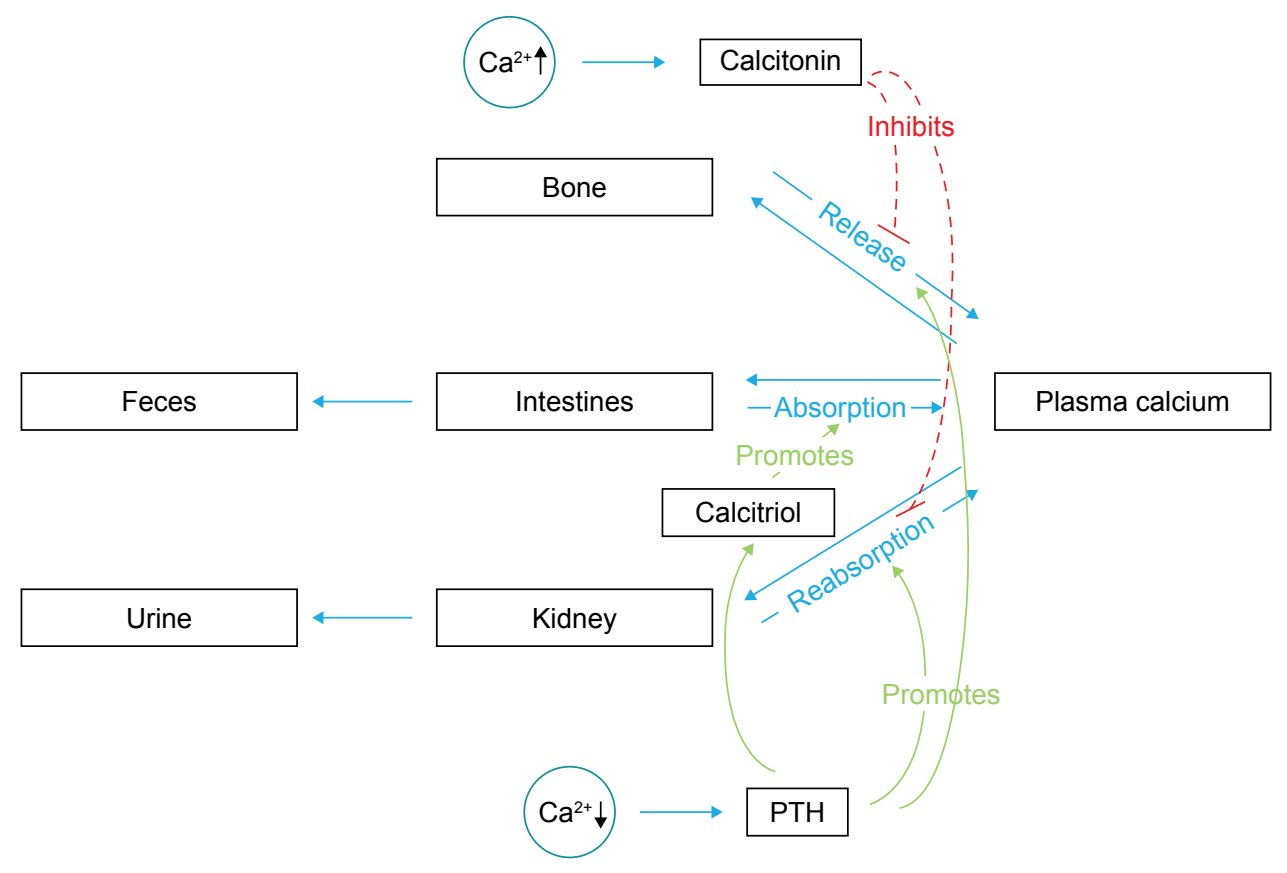

Figure I Schema of calcium metabolism and homeostasis in human body.

Notes: Dietary calcium is absorbed mainly in the small intestine and mostly deposited into bones. Excessive or unabsorbed calcium is excreted in urine and feces. Plasma calcium level is mainly maintained by both PTH and calcitonin. When serum calcium level drops, PTH promotes calcium releases from the bones and stimulates reabsorption of calcium by the kidney tubules. In addition, PTH indirectly increases calcium absorption in the intestine via calcitriol. On the other hand, when serum calcium level rises, calcitonin would suppress calcium release from the bones and reduce calcium reabsorption by the kidney tubules.

Abbreviation: PTH, parathyroid hormone.

trial did not persist when the calcium supplementation was discontinued. ${ }^{19}$ Taking all the evidence into account, these studies all suggested that calcium supplementation, either in the form of calcium supplements or dietary calcium, played a positive role in people of different ages and genders, even though those results were obtained from studies of different sample sizes.

\section{Postmenopausal women}

A randomized, double-blind, placebo-controlled study performed on 1,471 postmenopausal women with 5-year follow-up, receiving either $1,000 \mathrm{mg} / \mathrm{d}$ calcium supplements or identical placebo, showed that calcium supplements could decrease bone loss. ${ }^{20}$ One meta-analysis, which included 29 randomized trials with men and women aged $>50$ years (including menopausal women), indicated that adequate calcium intake with/without vitamin D is associated with a reduced risk of fractures of any type (the $R R=0.88,95 \%$ $\mathrm{CI}=0.83-0.95)$ as well as provided a modest benefit on reducing the rate of bone loss, with $0.54 \%$ reduction of bone loss in the hip and $1.19 \%$ reduction of bone loss in the spine. In addition, there was a $24 \%$ risk reduction in osteoporotic fractures in people with high compliance rate for calcium supplementation. Furthermore, this study also suggested that a minimum dose of $1,200 \mathrm{mg} / \mathrm{d}$ calcium with $800 \mathrm{IU} / \mathrm{d}$ vitamin D was the best treatment for osteoporosis. ${ }^{21}$ Most studies involving postmenopausal women did not conduct data stratification to address whether calcium supplementation had similar or different effects in those women with or without osteoporosis. A Spanish study demonstrated a high prevalence of low calcium intake and vitamin D deficiency in postmenopausal women with osteoporosis. ${ }^{22}$ Further studies are needed to determine whether higher dose of calcium supplementation would be beneficial in this patient population. In one study performed exclusively in the postmenopausal women with no history of osteoporosis, 187 women aged $>65$ years were enrolled in a descriptive cross-sectional trial, revealing that adequate calcium intake along with proper exercise can effectively prevent osteoporosis. ${ }^{23}$ The recommended dosage of calcium supplementation for postmenopausal women with or without osteoporosis has been supported by the results of some large studies; 36,282 postmenopausal women were randomized into various groups with $1,000 \mathrm{mg} / \mathrm{d}$ calcium and vitamin $\mathrm{D}$ or placebo and followed for 7 years in the largest study, suggesting that hip bone density was improved with calcium supplements. ${ }^{24}$ 


\section{Premenopausal women}

The current evidence is not sufficient to recommend calcium supplementation for the primary prevention of fractures in community-dwelling, asymptomatic premenopausal women. ${ }^{25}$ However, for those with a history of osteoporotic fractures, a diagnosis of osteoporosis, vitamin D deficiency, or a high risk for osteoporosis (eg, primary ovarian insufficiency), calcium supplementation may be considered. ${ }^{26,27}$

\section{Pregnant and lactating women}

There is still a lack of clinical data to recommend calcium supplementation in pregnant or lactating women for the skeletal health of fetus and mother. A Cochrane database systemic review found that calcium supplementation during pregnancy did not have any clear additional benefits in the prevention of preterm birth or low infant birthweight. ${ }^{28}$ However, in pregnant and lactating women with low calcium intakes, calcium supplementation may be considered. ${ }^{29}$ Interestingly, in a study in pregnancy women in Gambia, West Africa, with low calcium intakes, calcium supplement resulted in significantly lower bone mineral content, bone area, and BMD at the hip throughout 12-month lactation. The women also had greater decreases in bone mineral during lactation at the lumbar spine and distal radius and had biochemical changes consistent with greater bone mineral mobilization. ${ }^{30}$

\section{Men}

Although the evidence for preventing osteoporosis and improving BMD has been mostly generated in studies of postmenopausal women, a study back in 2008 compared the effects of two dosages of calcium citrate $(600 \mathrm{mg} / \mathrm{d}$, $1,200 \mathrm{mg} / \mathrm{d}$, or placebo) on BMD in healthy men. The double-blind, randomized controlled trial performed on 323 healthy men aged $>40$ years for a 2 -year period revealed that the $1,200 \mathrm{mg} / \mathrm{d}$ group showed increased BMD; however, it needs to be noted that urine calcium tended to increase by $57 \%$ correspondingly. ${ }^{31}$ In one study recently performed in Korean subjects, including 5,955 men, 1,256 premenopausal women and 4,494 postmenopausal women, it was revealed that increasing dietary calcium intake significantly improved BMD in both men and women. ${ }^{32}$

\section{Children}

In a study conducted in rural Gambian children accustomed to a low-calcium diet, calcium supplementation resulted in higher bone mineral content and BMD. ${ }^{33}$ For healthy children, there has been no recommendation for routine calcium supplementation. In clinical practice, children with a high risk of osteoporosis (eg, celiac disease, inflammatory bowel disease, or congenital bone disorder) or low calcium intake may benefit from calcium supplementation.

\section{Cardiovascular disease}

There is evidence suggesting that cardiovascular disease might be protected by calcium supplementation. A prospective cohort study conducted among an elderly Chinese population indicated that dietary calcium intake (mean $=600 \mathrm{mg} / \mathrm{d}$ ) could reduce the risk of death from all causes and cardiovascular diseases..$^{34}$ Despite the limitations (a self-administered questionnaire was used), its results added to the body of evidence that calcium supplementation decreases the mortality risk of cardiovascular diseases. Another prospective cohort study in Europe indicated that a daily administration of a mean of $820 \mathrm{mg}$ dietary calcium has an effect of up to a $30 \%$ decrease in the risk of myocardial infarction. ${ }^{35}$ Similarly, in a prospective cohort study performed exclusively in $>34,000$ postmenopausal women, both the high intake of dietary and supplemental calcium were associated with a decrease in the mortality of ischemic heart disease. ${ }^{36} \mathrm{It}$ was even observed that adverse cardiovascular effects were stopped after calcium supplements discontinued. ${ }^{19}$ Findings of these studies are likely to suggest that positive effects between calcium and cardiovascular diseases exist and that there is generally favorable evidence to imply that calcium influences cardiovascular disease occurrence. Calcium may slightly adjust lipid profiles and reduce blood pressure and more importantly - the risk of developing hypertension. ${ }^{37,38}$ In prospective studies, the risks for developing hypertension were reduced with calcium supplements in men and women. ${ }^{39,40}$ In addition, preeclampsia is characterized by hypertension and would lead to perinatal morbidity and mortality of both mothers and infants. ${ }^{41}$ In 2013, the World Health Organization published a strong recommendation that pregnant women should take calcium supplements to prevent preeclampsia. ${ }^{42}$ A randomized controlled trial in women suggested that calcium supplementation $>1,000 \mathrm{mg} / \mathrm{d}$ is associated with a significant reduction in the risk of preeclampsia. ${ }^{43}$

\section{Gastrointestinal disease}

The effect of dietary calcium intake on the colorectal cancer and a comparison with the effect of higher and lower level of dietary calcium have been investigated by Galas et al. ${ }^{44}$ They concluded that an increase of $100 \mathrm{mg}$ dietary calcium intake per day lowered by $5 \%$ the risk of colorectal 
cancer (OR $=0.95,95 \% \mathrm{CI}=0.92-0.99)$, and an increase of $1,000 \mathrm{mg} / \mathrm{d}$ dietary calcium consumption decreased incidence by $37 \%$ of colorectal cancer and the risk of colon cancer by $50 \%$. Simultaneously, dietary calcium $>1,000 \mathrm{mg} / \mathrm{d}$ decreased $46 \%$ incidence of colon cancer by $46 \%$ and the risk of colorectal cancer by $30 \%{ }^{44}$ A prospective cohort study revealed that the greatest benefits were observed with subjects who had highest dietary calcium intake (median $=914 \mathrm{mg} / \mathrm{d}$ ) compared with subjects who had lowest calcium intakes at a median level of $486 \mathrm{mg} /$ day. ${ }^{45}$

A similar effect was observed with calcium supplement. A randomized, double-blind trial performed on people with a history of colorectal adenomas, receiving either $1,200 \mathrm{mg} / \mathrm{d}$ elemental calcium or placebo, revealed a significant reduction in the risk of recurrent colorectal adenomas with calcium supplementation. ${ }^{46}$ The explanation behind those findings is the ability of calcium to combine with bile acids in the intestines, reducing the rectal epithelial proliferation rate. ${ }^{47}$ Most of the risk reduction benefit was achieved by calcium intake of at least $900 \mathrm{mg} /$ day. Lower calcium intake was reported to increase the risk of colorectal cancer in Korean individuals with the CC genotype of the CASR gene in the single nuclear polymorphism of rs2270916, compared with those in higher calcium intake with the TT genotype $(\mathrm{OR}=2.11,95 \% \mathrm{CI}=1.27-3.51){ }^{48}$

\section{Kidney stone}

Kidney stones are a common disease of the urinary system and are partially formed by calcium phosphate and calcium oxalate. Taylor and Curhan reported a relationship between calcium intake and urinary oxalate levels in a cross-sectional study. They concluded that high intake of dietary calcium or supplemental calcium $(>500 \mathrm{mg} / \mathrm{d}$ ) could lower urinary oxalate levels, subsequently decreasing the risk of kidney stones formation. ${ }^{49}$ Interestingly, a 12 -year prospective study of 91,731 women without a history of kidney stones with 12-year follow-up suggested that high dietary calcium could reduce the risk of kidney stones, whereas the risk would be increased in women with high supplemental calcium. ${ }^{50}$ The mechanism of the different results caused by different types of calcium on kidney stones has not been definitively determined, but it is likely that dietary calcium decreases the absorption of oxalate and is probably associated with the timing of calcium ingestion relative to the amount of oxalate consumed. Consequently, it is reasonable to speculate that the effect of supplemental calcium on kidney stone risk depends on whether supplements are received with or between meals.
Aside from its beneficial roles on people, calcium is also used in the management of hypoparathyroidism and osteomalacia. Calcium supplements are considered a standard treatment for hypocalcemia associated with postsurgical hypoparathyroidism and achieves better clinical results. ${ }^{51}$

\section{Potential adverse effects of calcium supplementation}

Despite the abovementioned studies providing powerful evidence for beneficial health-related effects of taking calcium, some recent evidence has implied that calcium supplementation might increase the risk for cardiovascular diseases and malignancy. What is more notable about these adverse effects is that, under the recommended dosage, calcium would produce some unwelcome reactions; therefore, a more detailed consideration of the safety and health benefits of calcium supplementation would be warranted. A number of adverse events are possibly influenced by calcium supplementation; these include myocardial infarction, constipation, colorectal neoplasms, and kidney stone. For example, in the Kuopio Osteoporosis Study, where 10,555 women were followed for 7 years, the HR for coronary heart disease in those who were taking calcium was 1.24 compared with nonusers. ${ }^{52}$ Thus, a doubt was for the first time raised in the beneficial effects of calcium supplementation on bone due to its adverse cardiovascular effects by this randomized control study. Moreover, a total of 1,460 postmenopausal women were randomized to taking calcium or a placebo and followed over 5 years, and the HR was found to be 1.12 for incident ischemic heart disease $(95 \% \mathrm{CI}=0.77-1.64) .{ }^{53}$ These surprising findings from the large related studies provide a stimulus for evaluating the effects of calcium on some disease events in other trials, which we describe below.

\section{Osteoporosis}

Although most studies indicate that calcium supplementation has a beneficial effect on osteoporosis and fractures, this statement is not confirmed by some other researches. Warensjö et al found that dietary calcium intake $<751 \mathrm{mg} / \mathrm{d}$ raised the risk of osteoporosis-related fractures and osteoporosis; meanwhile, intake $>1,137 \mathrm{mg} / \mathrm{d}$ would increase the risk of hip fractures in women..$^{54} \mathrm{~A}$ meta-analysis with seven cohorts totaling 170,991 women reported that calcium supplementation does not reduce the risk of hip fractures, and on the contrary, an increase in risk is possible. ${ }^{4}$ From these studies, the benefits of calcium supplementation become unclear, and there may be a therapeutic window where the greatest benefits on skeletal health are gained. Further research is needed to 
clarify this, with respect to dietary intake, ethnicity, race, age, and gender.

\section{Cardiovascular diseases}

The side effects of calcium have long been focused on cardiovascular diseases as the principal concern. Cardiovascular diseases, especially myocardial infarction and myocardial ischemia, are among the leading causes of death around the world. It is estimated by a meta-analysis (including eleven randomized controlled trials) that calcium supplements have up to $30 \%$ increase risk for myocardial infarction. ${ }^{55}$ It was noteworthy that men or women aged $>50$ years were recommended to take $\geq 1,000 \mathrm{mg} / \mathrm{d}$ calcium according to the guidelines $;{ }^{56}$ however, the risk of cardiovascular diseases appears to be particularly increased when those doses are actually used. A prospective study found that supplemental calcium intake of $>1,000 \mathrm{mg} / \mathrm{d}$ may raise the risk of death from cardiovascular diseases among men, but not among women. ${ }^{6}$ A randomized, placebo controlled trial performed on a population of 1,471 postmenopausal healthy women, with a follow-up that lasting 5 years, revealed that $1,000 \mathrm{mg} / \mathrm{d}$ elemental calcium supplements increased the incidence of cardiovascular events. ${ }^{57}$ In addition, a prospective observational study suggested that the use of calcium supplements in a long term would raise the risk of hospitalization in patients with chronic heart failure; for patients with diabetes, that risk was doubled. ${ }^{58}$ It is a remarkable fact that the effects of cardiovascular diseases between dietary and supplements of calcium lead to disparate results. A study indicated that the risk of myocardial infarction remarkably increased by taking calcium supplements compared with nonusers of any supplements $(\mathrm{HR}=1.86,95 \% \mathrm{CI}=1.17-2.96) .{ }^{35}$ The finding of an adverse trend in cardiovascular diseases with calcium supplementation is not necessarily surprising, as calcium supplements potentially contribute to elevated serum calcium levels and possibly accelerated cardiovascular calcification in the long run, ${ }^{59}$ which is predictive of cardiovascular event rates. ${ }^{60}$ Because of the high incidence of cardiovascular disease, any effects of calcium supplements on vascular health could be as important in terms of their effects on morbidity and mortality as their effects on osteoporosis or bone health. ${ }^{61}$ As these adverse effects are confirmed, a comprehensive reappraisal of taking calcium supplements may be required.

\section{Gastrointestinal diseases}

The second major safety concern with respect to calcium has been gastrointestinal diseases. The conclusion regarding the effects of calcium supplements on the gastrointestinal diseases is not totally consistent. Calcium supplements may increase the incidence of constipation, severe diarrhea, and abdominal pain. ${ }^{1,62}$ It highlights that calcium carbonate is more often associated with gastrointestinal side effects, including constipation, flatulence, and bloating. ${ }^{18}$ Of the 92,000 adverse events recorded, the occurrence of constipation was increased with calcium carbonate treatment $(1,200 \mathrm{mg} / \mathrm{d})$ in a 5 -year, double-blind, placebo-controlled study. ${ }^{53}$ Moreover, some studies demonstrated a negative correlation between the intake of calcium and colorectal adenoma. A meta-analysis of 24 studies exploring the relationship between calcium supplementation and colorectal adenoma implied that the pooled RR was 1.13 for the occurrence of colorectal adenoma (95\% CI $=0.91-1.39) .{ }^{63}$ As stated previously, these findings are inconsistent as other research has shown reduction in the risk of colorectal cancer with calcium supplements.

\section{Kidney stone}

The third major concern regarding the safety of calcium has been the occurrence of kidney stones. Despite that calcium has positive effects on kidney stones by some researches, the literature is not consistent regarding the relationship between calcium and kidney stone formation. It was found that the abnormality of urinary supersaturation is one of the main factors for the formation of kidney stones. ${ }^{64}$ Specifically, levels of supersaturation above 1 can easily result in crystal deposits and growth and are considered a high-risk factor in kidney stone formation. The formation of urinary calcium oxalate stones is probably related to abnormal oxalate metabolism. ${ }^{52}$ Of note, people lacking adequate calcium intake should carefully consider the intake of oxalate-rich foods, such as spinach, chocolates, and teas. ${ }^{53}$ While studies indicate the potential beneficial effects of dietary calcium intake on the reduction of the risk of kidney stones, individuals who consumed any amount of supplemental calcium had an increased risk for kidney stones compared with individuals who did not consume supplemental calcium. ${ }^{50} \mathrm{~A}$ study performed in 53 postmenopausal women with $1,000 \mathrm{mg} / \mathrm{d}$ calcium (with $400 \mathrm{IU} / \mathrm{d}$ vitamin D) for 1 year showed a weak relationship with kidney stones formation; only one patient with urinary calculi was proved by ultrasonography. However, the small sample size and short clinical trial duration may contribute to lack of significant findings in this study. ${ }^{65}$ Nonetheless, a study conducted in 2006, including 36,282 postmenopausal women aged 50-70 years followed up for an average of 7 years, receiving either $1,000 \mathrm{mg} / \mathrm{d}$ elemental calcium or placebo, found a $17 \%$ increased risk of developing kidney 
stones, with 449 women reporting kidney stones in the calcium with vitamin D group vs 381 women in the placebo group. ${ }^{24}$ Normally, stone formation in a normal kidney is relatively rare and is probably due to a combination of factors, such as health condition, urinary acidity, dietary habit, and variation in intake of calcium supplements (calcium oxalate, calcium citrate, and calcium carbonates). Dietary calcium is more beneficial for health in the aspect of kidney stone development. ${ }^{66}$

\section{Other diseases}

In addition, adverse effects of calcium on other diseases such as age-related macular degeneration (AMD) and metabolic syndrome were reported. A recent cross-sectional study found that $>800 \mathrm{mg} / \mathrm{d}$ of calcium consumption in people aged $>67$ years may increase the risk of AMD compared with those who do not take calcium $(\mathrm{OR}=2.63$, 95\% CI $=1.52-4.54) .{ }^{67}$ A study in Korea found that men taking dietary calcium $>1,200 \mathrm{mg} / \mathrm{d}$ had increased the prevalence of metabolic syndrome compared with those taking $<1,200 \mathrm{mg} / \mathrm{d}$, but no similar correlation was found in women. ${ }^{32}$

For ease of reference, we summarized the above most salient points for the benefits and adverse effects in Table 2.

\section{Conclusion}

The issue of safety in people receiving calcium has long been a matter of debate. There is an abundance of data for beneficial effects and side effects in the literature on the role of calcium. All taken together, it is important to balance the advantages and disadvantages of calcium supplementation on human health. Based the literature, calcium supplementation is a double-edged sword in promoting bone formation or preventing osteoporosis, as it also may have a potential negative impact.

Table 2 The effects of calcium supplementation in diseases

\begin{tabular}{|l|l|}
\hline Potential beneficial effects of calcium supplementation \\
\hline Diseases & References \\
\hline Osteoporosis & $19,20,21,24,32$ \\
\hline Cardiovascular disease & $34-36,43$ \\
\hline Gastrointestinal diseases & $44-46,48$ \\
\hline Kidney stones & 49,50 \\
\hline Potential adverse effects of calcium supplementation \\
\hline Osteoporosis & 4,54 \\
\hline Cardiovascular disease & $6,35,55,57$ \\
\hline Gastrointestinal diseases & 53,63 \\
\hline Kidney stones & 24,50 \\
\hline
\end{tabular}

Many factors could account for the inconsistencies in earlier studies. First, different dosages of calcium may induce different results. Second, dietary calcium may have beneficial effects than calcium supplements. Third, different populations and sample sizes may affect the results of studies. In the reported studies, sample sizes vary from several hundreds to several thousands. Last, there are still some unknown mechanisms affecting the results. Therefore, further experimental studies are necessary to decipher the mechanisms of the calcium intake affecting those diseases. As for the types of calcium to consume, a thorough search of the literature on calcium studies suggested that dietary calcium is more beneficial for health than calcium supplements and that it is also easier to absorb.

However, there is no denying that the favorable role of calcium is evident in people of all ages, not only in the postmenopausal women and elderly population but also in childhood and adolescence. For children and adolescents, sufficient calcium intake is important for building strong bone. For adults, sufficient calcium intake is necessary to prevent or delay the incidence of osteoporosis. The expert from NOF recommended $1,200 \mathrm{mg} / \mathrm{d}$ of calcium intake for women aged $>51$ years and men aged $>71$ years and $1,000 \mathrm{mg} / \mathrm{d}$ for men aged $>50$ years, ${ }^{56}$ but based on the abovementioned literature, the proper dosages of calcium supplementation for people are actually not clear, especially when considering its adverse health effects. Is it suitable for people with some diseases to take calcium, such as those at a high risk for heart failure as cardiovascular diseases are one of the top three causes of mortality currently? And if taking calcium is necessary for those people, what is the proper dosage? There appears to be no clear answer to questions like these. Therefore, we recommend that calcium supplementation should be prescribed cautiously and take into account the health status of individuals. Of note, the patients with hypercalcemia should avoid taking calcium supplements.

Osteoporosis is a systemic metabolic disease that severely impacts the quality of life in the middle-aged and elderly, which has gradually grown into one of the most serious problems in public health. The two studies demonstrated that calcium could prevent osteoporosis and osteoporotic fracture or improve BMD, but simultaneously also revealed the increase of the occurrence of cardiovascular diseases ${ }^{19}$ and increase in urine calcium level and subsequently in the risk of urinary calculi. ${ }^{24}$ The results stimulated our attention to evaluate whether the beneficial role in bone is greater than its side effects. Therefore, calcium is a double-edged sword, which may be both potentially crucial and perilous. 
Questions remain as to whether taking extra calcium as calcium supplements is helpful to the general population. What is the real value of calcium intake by supplements per day for different individuals? Could it do more harm rather than good, particularly taking into consideration the increased risk of other diseases? More studies are needed to examine these effects for making better recommendations in different genders, ages, and ethnicities.

\section{Acknowledgments}

HWD and LJZ were partially supported by grants from the National Institutes of Health (AR069055, U19 AG055373, R01 MH104680, R01AR059781 and P20GM109036), the Edward G. Schlieder Endowment fund and the Tsai and Kung endowment fund to Tulane University.

\section{Author contributions}

HWD contributed to study conception, initiation, general development, and design. KL, XFW, YCC, YFG, and RZ collected data. XFW, DYL, YCC, XGL, LJZ, and YFG drafted the manuscript. KL, XFW, DYL, YCC, XGL, LJZ, JS, and HWD revised the final manuscript. All authors contributed to data analysis, drafting and revising the article, gave final approval of the version to be published, and agree to be accountable for all aspects of the work.

\section{Disclosure}

The authors report no conflicts of interest in this work.

\section{References}

1. Reid IR. Should we prescribe calcium supplements for osteoporosis prevention? J Bone Metab. 2014;21(1):21-28.

2. Gahche J, Bailey R, Burt V, et al. Dietary supplement use among U.S. adults has increased since NHANES III (1988-1994). NCHS Data Brief. 2011;61:1-8.

3. Booth A, Camacho P. A Closer look at calcium absorption and the benefits and risks of dietary versus supplemental calcium. Postgrad Med. 2013;125(6):73-81.

4. Bischoff-Ferrari HA, Dawson-Hughes B, Baron JA, et al. Calcium intake and hip fracture risk in men and women: a meta-analysis of prospective cohort studies and randomized controlled trials. Am J Clin Nutr. 2007;86(6):1780-1790.

5. Zhao JG, Zeng XT, Wang J, Liu L. Association Between Calcium or Vitamin D Supplementation and Fracture Incidence in CommunityDwelling Older Adults: A Systematic Review and Meta-analysis. JAMA. 2017;318(24):2466-2482.

6. Xiao Q, Murphy RA, Houston DK, Harris TB, Chow WH, Park Y. Dietary and supplemental calcium intake and cardiovascular disease mortality: the National Institutes of Health-AARP diet and health study. JAMA Intern Med. 2013;173(8):639-646.

7. Tankeu AT, Ndip Agbor V, Noubiap JJ. Calcium supplementation and cardiovascular risk: A rising concern. J Clin Hypertens. 2017;19(6): 640-646.

8. Reid IR, Birstow SM, Bolland MJ. Calcium and Cardiovascular Disease. Endocrinol Metab. 2017;32(3):339-349.
9. Emkey RD, Emkey GR. Calcium metabolism and correcting calcium deficiencies. Endocrinol Metab Clin North Am. 2012;41(3): $527-556$.

10. Institute of Medicine (US) Committee to Review Dietary Reference Intakes for Vitamin D and Calcium. Dietary Reference Intakes for Calcium and Vitamin D. (Ross AC, Taylor CL, Yaktine AL, Del Valle HB, eds.). Washington, DC: National Academies Press; 2011. Available from: http://www.ncbi.nlm.nih.gov/books/NBK56070/. Accessed September 13, 2018.

11. Brini M, Calì T, Ottolini D, Carafoli E. Intracellular calcium homeostasis and signaling. Met Ions Life Sci. 2013;12:119-168.

12. Krebs J, Agellon LB, Michalak M. Ca(2+) homeostasis and endoplasmic reticulum (ER) stress: An integrated view of calcium signaling. Biochem Biophys Res Commun. 2015;460(1):114-121.

13. Kleeman CR, Massry SG, Coburn JW. The clinical physiology of calcium homeostasis, parathyroid hormone, and calcitonin. I. Calif Med. 1971;114(3):16-43.

14. Blaine J, Chonchol M, Levi M. Renal control of calcium, phosphate, and magnesium homeostasis. Clin J Am Soc Nephrol. 2015; 10(7):1257-1272.

15. Watts NB, Bilezikian JP, Camacho PM, et al; AACE Osteoporosis Task Force. American Association of Clinical Endocrinologists Medical Guidelines for Clinical Practice for the diagnosis and treatment of postmenopausal osteoporosis. Endocr Pract. 2010;16(Suppl 3):1-37.

16. Weaver CM, Gordon CM, Janz KF, et al. The National Osteoporosis Foundation's position statement on peak bone mass development and lifestyle factors: a systematic review and implementation recommendations. Osteoporos Int. 2016;27(4):1281-1386.

17. Harvey NC, Biver E, Kaufman JM, et al. The role of calcium supplementation in healthy musculoskeletal ageing: An expert consensus meeting of the European Society for Clinical and Economic Aspects of Osteoporosis, Osteoarthritis and Musculoskeletal Diseases (ESCEO) and the International Foundation for Osteoporosis (IOF). Osteoporos Int. 2017;28(2):447-462.

18. Straub DA. Calcium supplementation in clinical practice: a review of forms, doses, and indications. Nutr Clin Pract. 2007;22(3):286-296.

19. Radford LT, Bolland MJ, Mason B, et al. The Auckland calcium study: 5-year post-trial follow-up. Osteoporos Int. 2014;25(1):297-304.

20. Reid IR, Mason B, Horne A, et al. Randomized controlled trial of calcium in healthy older women. Am J Med. 2006;119(9):777-785.

21. Tang BM, Eslick GD, Nowson C, Smith C, Bensoussan A. Use of calcium or calcium in combination with vitamin $\mathrm{D}$ supplementation to prevent fractures and bone loss in people aged 50 years and older: a meta-analysis. Lancet. 2007;370(9588):657-666.

22. Quesada-Gómez JM, Diaz-Curiel M, Sosa-Henriquez M, et al. Low calcium intake and inadequate vitamin D status in postmenopausal osteoporotic women. J Steroid Biochem Mol Biol. 2013;136: 175-177.

23. Swaim RA, Barner JC, Brown CM. The relationship of calcium intake and exercise to osteoporosis health beliefs in postmenopausal women. Res Social Adm Pharm. 2008;4(2):153-163.

24. Jackson RD, LaCroix AZ, Gass M, et al; Women's Health Initiative Investigators. Calcium plus vitamin D supplementation and the risk of fractures. N Engl J Med. 2006;354(7):669-683.

25. US Preventive Services Task Force, Grossman DC, Curry SJ, et al. Vitamin D, Calcium, or Combined Supplementation for the Primary Prevention of Fractures in Community-Dwelling Adults: US Preventive Services Task Force Recommendation Statement. JAMA. 2018; 319(15):1592-1599.

26. Islam MZ, Shamim AA, Viljakainen HT, et al. Effect of vitamin D, calcium and multiple micronutrient supplementation on vitamin $\mathrm{D}$ and bone status in Bangladeshi premenopausal garment factory workers with hypovitaminosis $\mathrm{D}$ : a double-blinded, randomised, placebo-controlled 1-year intervention. Br J Nutr. 2010;104(2):241-247.

27. Marino R, Misra M. Bone health in primary ovarian insufficiency. Semin Reprod Med. 2011;29(4):317-327. 
28. Buppasiri P, Lumbiganon P, Thinkhamrop J, Ngamjarus C, Laopaiboon M. Calcium supplementation (other than for preventing or treating hypertension) for improving pregnancy and infant outcomes. Cochrane Database Syst Rev. 2011;10(10):CD007079.

29. Thomas M, Weisman SM. Calcium supplementation during pregnancy and lactation: effects on the mother and the fetus. Am J Obstet Gynecol. 2006;194(4):937-945.

30. Jarjou LM, Laskey MA, Sawo Y, Goldberg GR, Cole TJ, Prentice A. Effect of calcium supplementation in pregnancy on maternal bone outcomes in women with a low calcium intake. Am J Clin Nutr. 2010; 92(2):450-457.

31. Reid IR, Ames R, Mason B, et al. Randomized controlled trial of calcium supplementation in healthy, nonosteoporotic, older men. Arch Intern Med. 2008;168(20):2276-2282.

32. Noe EB, Chon SJ, Kim MK, et al. Associations between dietary calcium intake with prevalence of metabolic syndrome and changes in bone mineral density among Korean population. Maturitas. 2015; 81(1):171.

33. Dibba B, Prentice A, Ceesay M, Stirling DM, Cole TJ, Poskitt EM. Effect of calcium supplementation on bone mineral accretion in gambian children accustomed to a low-calcium diet. Am J Clin Nutr. 2000;71(2):544-549.

34. Chan R, Leung J, Woo J. A prospective cohort study examining the associations of dietary calcium intake with all-cause and cardiovascular mortality in older Chinese community-dwelling people. PLoS One 2013;8(11):e80895.

35. Li K, Kaaks R, Linseisen J, Rohrmann S. Associations of dietary calcium intake and calcium supplementation with myocardial infarction and stroke risk and overall cardiovascular mortality in the Heidelberg cohort of the European Prospective Investigation into Cancer and Nutrition study (EPIC-Heidelberg). Heart. 2012;98(12):920-925.

36. Bostick RM, Kushi LH, Wu Y, Meyer KA, Sellers TA, Folsom AR. Relation of calcium, vitamin $\mathrm{D}$, and dairy food intake to ischemic heart disease mortality among postmenopausal women. Am J Epidemiol. 1999;149(2):151-161.

37. Reid IR, Mason B, Horne A, et al. Effects of calcium supplementation on serum lipid concentrations in normal older women: a randomized controlled trial. Am J Med. 2002;112(5):343-347.

38. Reid IR, Horne A, Mason B, Ames R, Bava U, Gamble GD. Effects of calcium supplementation on body weight and blood pressure in normal older women: a randomized controlled trial. J Clin Endocrinol Metab. 2005;90(7):3824-3829.

39. Witteman JC, Willett WC, Stampfer MJ, et al. A prospective study of nutritional factors and hypertension among US women. Circulation. 1989; 80(5):1320-1327.

40. Ascherio A, Rimm EB, Giovannucci EL, et al. A prospective study of nutritional factors and hypertension among US men. Circulation. 1992;86(5):1475-1484.

41. Duhig KE, Shennan AH. Recent advances in the diagnosis and management of pre-eclampsia. F1000 Prime Rep. 2015;7:24.

42. World Health Organization. Guideline: Calcium Supplementation in Pregnant Women. Geneva: World Health Organization; 2013. Available from: http://www.ncbi.nlm.nih.gov/books/NBK154180/. Accessed September 13, 2018

43. Hofmeyr GJ, Atallah AN, Duley L. Calcium supplementation during pregnancy for preventing hypertensive disorders and related problems. Cochrane Database Syst Rev. 2006;3(3):CD001059.

44. Galas A, Augustyniak M, Sochacka-Tatara E. Does dietary calcium interact with dietary fiber against colorectal cancer? A case-control study in Central Europe. Nutr J. 2013;12:134.

45. Terry P, Baron JA, Bergkvist L, Holmberg L, Wolk A. Dietary calcium and vitamin $\mathrm{D}$ intake and risk of colorectal cancer: a prospective cohort study in women. Nutr Cancer. 2002;43(1):39-46.

46. Baron JA, Beach M, Mandel JS, et al. Calcium supplements for the prevention of colorectal adenomas. Calcium Polyp Prevention Study Group. N Engl J Med. 1999;340(2):101-107.
47. Welberg JWM, Kleibeuker JH, Dermeer RV, Mulder NH, de Vries EGE, Vries E. Calcium and the Prevention of Colon Cancer. Scand J Gastroenterol. 1991;26(Sup 188):52-59.

48. Kim KZ, Shin A, Kim J, et al. Association between CASR polymorphisms, calcium intake, and colorectal cancer risk. PLoS One. 2013; 8(3):e59628.

49. Taylor EN, Curhan GC. Determinants of 24-hour urinary oxalate excretion. Clin J Am Soc Nephrol. 2008;3(5):1453-1460.

50. Curhan GC, Willett WC, Speizer FE, Spiegelman D, Stampfer MJ. Comparison of dietary calcium with supplemental calcium and other nutrients as factors affecting the risk for kidney stones in women. Ann Intern Med. 1997;126(7):497-504.

51. Khan MI, Waguespack SG, Hu MI, Mi H. Medical management of postsurgical hypoparathyroidism. Endocr Pract. 2011;17(Suppl 1):18-25.

52. Pentti K, Tuppurainen MT, Honkanen R, et al. Use of calcium supplements and the risk of coronary heart disease in 52-62-year-old women: The Kuopio Osteoporosis Risk Factor and Prevention Study. Maturitas. 2009;63(1):73-78.

53. Prince RL, Devine A, Dhaliwal SS, Dick IM. Effects of calcium supplementation on clinical fracture and bone structure: results of a 5-year, double-blind, placebo-controlled trial in elderly women. Arch Intern Med. 2006;166(8):869-875.

54. Warensjö E, Byberg L, Melhus H, et al. Dietary calcium intake and risk of fracture and osteoporosis: prospective longitudinal cohort study. BMJ. 2011;342:d1473.

55. Bolland MJ, Avenell A, Baron JA, et al. Effect of calcium supplements on risk of myocardial infarction and cardiovascular events: metaanalysis. BMJ. 2010;341:c3691.

56. Cosman F, de Beur SJ, LeBoff MS, et al; National Osteoporosis Foundation. Clinician's Guide to Prevention and Treatment of Osteoporosis. Osteoporos Int. 2014;25(10):2359-2381.

57. Bolland MJ, Barber PA, Doughty RN, et al. Vascular events in healthy older women receiving calcium supplementation: randomised controlled trial. BMJ. 2008;336(7638):262-266.

58. Drozd M, Cubbon R, Gierula J, et al. 54 Calcium Supplementation in Patients with Chronic Heart Failure: Is it Safe? Heart. 2014; 100(Suppl 3):A31.

59. West SL, Swan VJ, Jamal SA. Effects of calcium on cardiovascular events in patients with kidney disease and in a healthy population. Clin J Am Soc Nephrol. 2010;5(Suppl 1):S41-S47.

60. Meier C, Kränzlin ME. Calcium supplementation, osteoporosis and cardiovascular disease. Swiss Med Wkly. 2011;141:w13260.

61. Michaëlsson K, Melhus H, Warensjö Lemming E, Wolk A, Byberg L. Long term calcium intake and rates of all cause and cardiovascular mortality: community based prospective longitudinal cohort study. BMJ. 2013;346:f228.

62. Lewis JR, Zhu K, Prince RL. Adverse events from calcium supplementation: relationship to errors in myocardial infarction self-reporting in randomized controlled trials of calcium supplementation.J Bone Miner Res. 2012;27(3):719-722.

63. Bergsma-Kadijk JA, van't Veer P, Kampman E, Burema J. Calcium does not protect against colorectal neoplasia. Epidemiology. 1996; 7(6):590-597.

64. Worcester EM, Coe FL. Clinical practice. Calcium kidney stones. N Engl J Med. 2010;363(10):954-963.

65. Haghighi A, Samimagham H, Gohardehi G. Calcium and vitamin D supplementation and risk of kidney stone formation in postmenopausal women. Iran J Kidney Dis. 2013;7(3):210-213.

66. Favus MJ. The risk of kidney stone formation: the form of calcium matters. Am J Clin Nutr. 2011;94(1):5-6.

67. Kakigi CL, Singh K, Wang SY, Enanoria WT, Lin SC. Self-reported Calcium Supplementation and Age-Related Macular Degeneration. JAMA Ophthalmol. 2015;133(7):746-754.

68. Compston J, Cooper A, Cooper C, et al. UK clinical guideline for the prevention and treatment of osteoporosis. Arch Osteoporos. 2017;12(1):43 
69. Osteoporosis.org.nz. Guidance on the Diagnosis and Management of Osteoporosis in New Zealand. Available from: http://osteoporosis. org.nz/resources/health-professionals/clinical-guidance/. Accessed September 13, 2018.

70. Orimo H, Nakamura T, Hosoi T, et al. Japanese 2011 guidelines for prevention and treatment of osteoporosis - executive summary. Arch Osteoporos. 2012;7(1-2):3-20.

71. Makras P, Vaiopoulos G, Lyritis GP. 2011 guidelines for the diagnosis and treatment of osteoporosis in Greece. J Musculoskelet Neuronal Interact. 2012;12(1):38-42.
72. Chinese Society of Osteoporosis and Bone Mineral Research. Guideline of diagnosis and treatment of primary osteoporosis. Chin J Osteoporos Bone Miner Res. 2011;4(1):2-17.

73. Papaioannou A, Morin S, Cheung AM, et al. 2010 clinical practice guidelines for the diagnosis and management of osteoporosis in Canada: summary. Can Med Assoc J. 2010;182(17):1864-1873.

\section{Publish your work in this journal}

Clinical Interventions in Aging is an international, peer-reviewed journal focusing on evidence-based reports on the value or lack thereof of treatments intended to prevent or delay the onset of maladaptive correlates of aging in human beings. This journal is indexed on PubMed Central, MedLine,
CAS, Scopus and the Elsevier Bibliographic databases. The manuscript management system is completely online and includes a very quick and fair peer-review system, which is all easy to use. Visit http://www.dovepress. com/testimonials.php to read real quotes from published authors. 